\section{(6) OPEN ACCESS}

\title{
Transcranial magnetic stimulation and amyotrophic lateral sclerosis: pathophysiological insights
}

\author{
Steve Vucic, ${ }^{1,2}$ Ulf Ziemann, ${ }^{3}$ Andrew Eisen, ${ }^{4}$ Mark Hallett, ${ }^{5}$ Matthew C Kiernan ${ }^{2,6}$
}

'Sydney Medical School Westmead, University of Sydney, Sydney, New South Wales, Australia

${ }^{2}$ Neuroscience Research Australia, Sydney, New South Wales, Australia

${ }^{3}$ Department of Neurology and

Stroke, Hertie Institute for Clinical Brain Research,

Eberhard-Karls University, Tübingen, Germany

${ }^{4}$ Division of Neurology, The University of British Columbia, Vancouver, British Columbia, Canada

${ }^{5}$ Human Motor Control Section, NINDS, NIH, Bethesda, Maryland, USA ${ }^{6}$ Prince of Wales Clinical School, University of New South Wales, Sydney, New South Wales, Australia

\section{Correspondence to} Associate Professor Steve Vucic, Sydney Medical School Westmead, University of Sydney, Darcy and Hawkesbury Rd, Wentworthville, Sydney, NSW 2045, Australia; s.vucic@ neura.edu.au

Received 20 September 2012 Revised 20 November 2012 Accepted 25 November 2012 Published Online First

21 December 2012

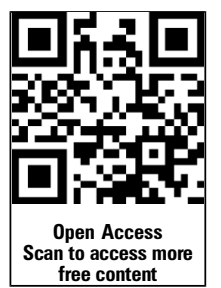

To cite: Vucic $S$

Ziemann U, Eisen A, et al. J Neurol Neurosurg Psychiatry 2013;84:1161-1170.

\section{ABSTRACT}

Amyotrophic lateral sclerosis (ALS) is a rapidly progressive neurodegenerative disorder of the motor neurons in the motor cortex, brainstem and spinal cord. A combination of upper and lower motor neuron dysfunction comprises the clinical ALS phenotype. Although the ALS phenotype was first observed by Charcot over 100 years ago, the site of ALS onset and the pathophysiological mechanisms underlying the development of motor neuron degeneration remain to be elucidated. Transcranial magnetic stimulation (TMS) enables non-invasive assessment of the functional integrity of the motor cortex and its corticomotoneuronal projections. To date, TMS studies have established motor cortical and corticospinal dysfunction in ALS, with cortical hyperexcitability being an early feature in sporadic forms of ALS and preceding the clinical onset of familial ALS. Taken together, a central origin of ALS is supported by TMS studies, with an anterograde transsynaptic mechanism implicated in ALS pathogenesis. Of further relevance, TMS techniques reliably distinguish ALS from mimic disorders, despite a compatible peripheral disease burden, thereby suggesting a potential diagnostic utility of TMS in ALS. This review will focus on the mechanisms underlying the generation of TMS measures used in assessment of cortical excitability, the contribution of TMS in enhancing the understanding of ALS pathophysiology and the potential diagnostic utility of TMS techniques in ALS.

\section{INTRODUCTION}

The term amyotrophic lateral sclerosis (ALS) was first coined by Charcot, who postulated the primacy of the upper motor neuron (UMN) in ALS pathogenesis. ${ }^{1}$ Assessment of cortical function in ALS and identification of the characteristic clinical phenotype involving combined upper and lower motor neuron abnormalities remain the key for ALS diagnosis. ${ }^{2-4}$ However, despite Charcot's initial observations, the site of disease onset and mechanisms underlying ALS pathophysiology remain areas of intense study and debate. ${ }^{5}$ In this setting, assessment of motor cortical and corticospinal function using non-invasive techniques, such as transcranial magnetic stimulation (TMS), has enhanced our understanding of ALS pathophysiology and resulted in novel diagnostic approaches.

Single-, paired- and multiple-pulse TMS techniques have all been used (figure 1) with the following measures taken to reflect corticomotoneuronal function: motor threshold (MT), motor evoked potential (MEP) amplitude, central motor conduction time (CMCT), cortical silent period (CSP), intracortical inhibition and facilitation. The present review will focus on the mechanisms underlying the generation of these TMS measures, while at the same time assessing the contributions TMS has made in the understanding of ALS pathophysiology. With an eye towards the future, the review will also consider the potential diagnostic utility of TMS in ALS and incorporation of TMS as a disease biomarker in the assessment of neuroprotective medications in a clinical trial setting.

\section{BACKGROUND TMS TERMINOLOGY AND PATHOPHYSIOLOGY}

$M T$ reflects the ease with which corticomotoneurons are excited and is proposed to be assessed by the International Federation of Clinical Neurophysiology as the minimum stimulus intensity required to elicit a small (usually $>50 \mu \mathrm{V}$ ) MEP in the target muscle in $50 \%$ of trials. ${ }^{6}$ With the recent adaptation of threshold tracking techniques, MT can also be measured as the stimulus intensity required to elicit and maintain a target MEP response of $0.2 \mathrm{mV}^{7-9}$ MT reflects the density of corticomotoneuronal projections onto the spinal motor neuron with the highest density of projections to intrinsic hand muscles having the lowest MTs. ${ }^{10-12}$ MTs are lower in the dominant hand ${ }^{12}$ and correlate with the ability to perform fine (fractionated) finger tasks, ${ }^{13}$ so that MT has the potential to map corticomotoneuronal representation and function.

As well as reflecting the density of corticomotoneuronal projections, MTs may also be a biomarker of cortical neuronal membrane excitability. ${ }^{14-16}$ MTs are influenced by the glutamatergic neurotransmitter system, through $\alpha$-amino-3-hydroxy-5methyl-4-isoxazoleproprionic acid (AMPA) receptors, whereby excessive glutamate activity reduces MTs. ${ }^{17}$ In contrast, pharmacological blockade of voltagegated sodium channels raises MT. ${ }^{18}$

In ALS, abnormalities in MT have been inconsistent. While some TMS studies reported an increased MT or even an inexcitable motor cortex, ${ }^{19-26}$ others have documented either normal or reduced $\mathrm{MT}^{27-32}$ These discrepancies likely relate to heterogeneity of the ALS phenotype and the stage of disease at time of testing and rate of progression. Longitudinal studies have documented a reduction of MTs early in the disease course, increasing to the point of cortical inexcitability with disease progression. ${ }^{29}$ The early reduction in MT appears most pronounced in ALS patients with profuse fasciculations, preserved muscle bulk and hyper-reflexia. ${ }^{33}$ Fasciculations may precede other features of ALS by many months and taken in association with reduced 


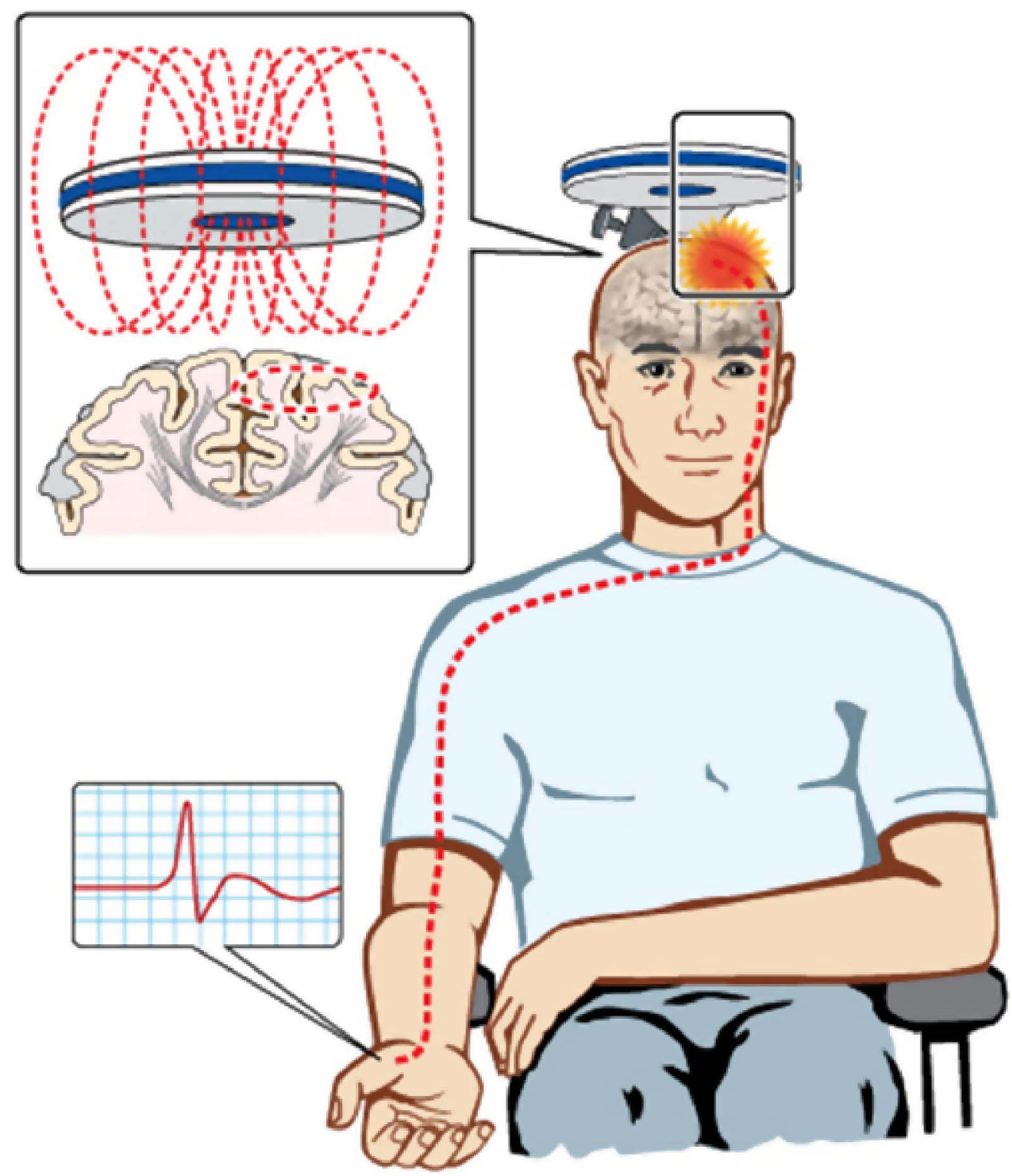

Figure 1 Transcranial magnetic stimulation excites a network of neurons in the underlying motor cortex with motor evoked potentials recorded over the contralateral abductor pollicis brevis muscle. The motor cortex is preferentially stimulated when the current flows in a posterior-anterior direction within the motor cortex.

MT suggest a cortical origin of fasciculations in ALS. ${ }^{34}$ Reduced MT may be modulated by increased glutamate excitation, reduced gamma-Aminobutyric acid (GABA) inhibition or a combination of both. Reduced MT early in ALS supports an anterograde transsynaptic process, whereby cortical hyperexcitability underlies the development of progressive neurodegeneration.

MEP amplitude reflects a summation of complex corticospinal volleys consisting of D (direct)- and I (indirect)-waves. ${ }^{14} 35 \mathrm{At}$ threshold, TMS elicits I-waves at intervals of $1.5 \mathrm{~ms}$, which increase in amplitude with increasing stimulus intensity. ${ }^{35}$ The increase in MEP amplitude with increasing stimulus intensity may be used to generate a stimulus-response curve that follows a sigmoid function. ${ }^{36}$ As with MT, the MEP amplitude reflects the density of corticomotoneuronal projections onto motor neurons. ${ }^{37}$ When compared with MT, the MEPs probably assess the function of neurons that are less excitable or further away from the centre of the TMS induced electrical field. ${ }^{38}$ The MEP amplitude should be expressed as a percentage of the maximum compound muscle action potential (CMAP) evoked by electrical peripheral nerve stimulation. ${ }^{6}$ Doing so takes into account any lower motor neuron pathology and provides insight into the percentage of the motor neurone pool activated in the MEP. Normative values for the MEP to CMAP ratio demonstrate a large inter-subject variability thereby reducing the sensitivity and limiting the value of this measure for detecting abnormalities of the corticomotoneurons. ${ }^{38} 39$

The MEP responses are modulated by a variety of neurotransmitter systems within the central nervous system. ${ }^{37} 40$ Specifically, GABAergic neurotransmission via $\mathrm{GABA}_{\mathrm{A}}$ receptors suppresses while glutamatergic and noradrenergic neurotransmission enhances the MEP amplitude. ${ }^{41}$ Of interest, these changes in MEP amplitude occur independently of changes in MT, suggesting that physiological mechanisms underlying the generation of the MEP amplitude and MT are varied. 
Abnormalities of MEPs have been extensively documented in ALS. ${ }^{38}$ Increases in MEP amplitude have been reported in sporadic and familial forms of ALS (figure 2A), most prominently early in the disease course. ${ }^{30} 3142$ MEP amplitude correlates with surrogate biomarkers of axonal degeneration, such as the strength duration time constant, thereby providing an association between cortical hyperexcitability and motor neuron degeneration. ${ }^{30}{ }^{43}$ The increase in MEP amplitude in ALS is not seen in mimic disorders despite a comparable degree of lower motor neuron dysfunction (figure 2B). This suggests that the MEP amplitude changes in ALS are excitotoxic in nature. ${ }^{44-47}$

CMCT represents the time from stimulation of the motor cortex to the arrival of corticospinal volley at the spinal motor neuron. ${ }^{6}$ Multiple factors contribute to the CMCT including time to activate the corticospinal cells, conduction time of the descending volley down the corticospinal tract, synaptic transmission and activation of spinal motor neurons. ${ }^{48}$ CMCT may be measured using either the F-wave or cervical (or lumbar) nerve root stimulation methods; ${ }^{49} 50$ both methods provide only an estimation of the CMCT, ${ }^{48} 51$ and given that a variety of technical, physiological and pathological factors influence $\mathrm{CMCT}^{48}$ there is a range of normative data.

In ALS, CMCT is typically modestly prolonged, ${ }^{21} 2952$ probably reflecting axonal degeneration of the fastest conducting corticomotoneuronal fibres and increased desynchronisation of corticomotoneuronal volleys secondary to axonal loss. ${ }^{28} 5354$ The D90A-SOD1 ALS mutation is a unique exception; in this disorder CMCT is typically very prolonged. ${ }^{55}$ The sensitivity of detecting a prolonged CMCT may be improved by recording from both upper and lower limb muscles, or from cranial muscles in ALS patients with bulbar onset disease. ${ }^{2656}$

CSP refers to the interruption of voluntary electromyography activity in a target muscle induced by stimulation of the
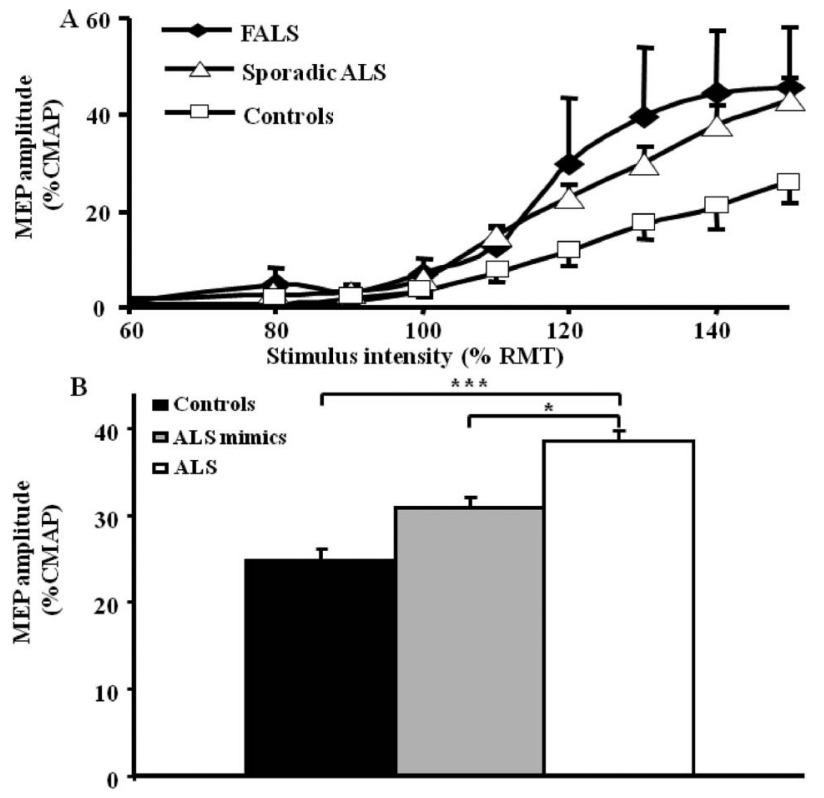

Figure 2 (A) The motor evoked potential (MEP) amplitude, expressed as a percentage of compound muscle action potential (CMAP) response, is significantly increased in sporadic amyotrophic lateral sclerosis (ALS) and familial ALS (FALS) when compared with healthy controls. (B) The MEP amplitude is significantly increased in ALS when compared with pathological and healthy controls, thereby distinguishing ALS from ALS mimic disorders. ${ }^{*} p<0.05 ;{ }^{* * *} p<0.001$. RMT, resting motor threshold. contralateral motor cortex. ${ }^{57}$ The CSP duration is measured from the onset of the MEP response to resumption of voluntary electromyography activity ${ }^{37} 57$ and increases with stimulus intensity. ${ }^{57-59}$

The CSP is mediated by both spinal mechanisms, in its early part, and cortical inhibitory neurons acting via $\mathrm{GABA}_{\mathrm{B}}$ receptors in the latter part. ${ }^{57} 58$ 60-63 Since the duration is determined by the latter part, the CSP is a measure of cortical inhibition. In addition, the density of the corticomotoneuronal projections onto motor neurons also influences the CSP, with the CSP duration being the longest for upper limb muscles. ${ }^{38}$

Abnormalities of the CSP duration are well established in ALS. ${ }^{37}$ Absence or reduction in CSP duration has been reported in both sporadic and familial ALS, with the reduction of CSP duration being the most prominent early in the disease course. $^{30-32} 44 \quad 46 \quad 52$ 64-67 The reduction of CSP duration appears to be specific for ALS among neuromuscular disorders, being normal in X-linked bulbospinal muscular atrophy (Kennedy's disease), acquired neuromyotonia and distal hereditary motor neuronopathy with pyramidal features. ${ }^{44-47}$ Although the mechanisms underlying CSP duration reduction in ALS remain to be established, decreased motor drive and reduced GABAergic inhibition, either due to degeneration of inhibitory interneurons or dysfunction of $\mathrm{GABA}_{\mathrm{B}}$ receptors, may underlie the reduction of CSP duration in ALS.

An absent or delayed ipsilateral CSP has also been reported as an early abnormality in ALS. ${ }^{67} 68$ The ipsilateral CSP depends on functioning of transcallosal glutamatergic fibres projecting onto inhibitory interneurons in the non-stimulated motor cortex, ${ }^{69}$ and degeneration of these transcallosal fibres or their targeted inhibitory interneurons may account for abnormalities of the ipsilateral CSP in ALS.

\section{PAIRED-PULSE TMS TECHNIQUES}

The previous section has covered conventional TMS parameters that can be assessed through activation of the motor cortex by single impulses. Motor cortical excitability may also be assessed using paired-pulse techniques, in which a conditioning stimulus modulates the effect of a second test stimulus. Several different paired-pulse paradigms have been developed, ${ }^{37} 38$ but short interval intracortical inhibition (SICI), intracortical facilitation (ICF) and long interval intracortical inhibition have been most frequently used in ALS clinical research as methods to determine cortical excitability.

To identify SICI and ICF, a subthreshold conditioning stimulus is typically delivered at predetermined time intervals prior to a suprathreshold test stimulus. ${ }^{8}{ }^{70-72}$ In the early TMS paradigms, ${ }^{70} 7273$ the conditioning and test stimuli were kept constant, and changes in the test MEP amplitude were evaluated. Typically, if the interstimulus interval (ISI) was between 1 and $5 \mathrm{~ms}$, the test response was inhibited (SICI). Increasing the ISI to between 7 and $30 \mathrm{~ms}$ resulted in the facilitation of the test response $(I C F){ }^{38}$

By recording the descending corticospinal volleys through epidural electrodes at the level of the cervical spinal cord, it has been deduced that both SICI and ICF originate at the level of the motor cortex. ${ }^{35} 72$ Specifically, SICI is associated with a reduction in the number and amplitude of late I-waves, namely I2 and I3, with I-wave suppression remaining up to an ISI of $20 \mathrm{~ms}$, which is the typical duration of the inhibitory postsynaptic potential mediated through $\mathrm{GABA}_{\mathrm{A}}$ receptors. ${ }^{71}{ }^{74} \mathrm{SICI}$ and ICF appear to be physiologically distinct processes as evident by lower thresholds for activation of SICI and SICI remains independent of the direction of current flow in the motor cortex 
induced by a subthreshold conditioning pulse in healthy subjects, while ICF appears to be preferentially generated by current flowing in a posterior-anterior direction. ${ }^{73}$

A limitation of the 'constant stimulus' paired-pulse technique has been the marked variability in MEP amplitudes with consecutive stimuli. $^{71} 75$ To overcome this limitation, a threshold tracking technique was developed whereby a constant target MEP response $(0.2 \mathrm{mV})$ was tracked by a test stimulus. ${ }^{78}$ Using threshold tracking, two phases of SICI were identified, ${ }^{787677}$ a smaller phase at ISI $\leq 1 \mathrm{~ms}$ and a larger phase at ISI $3 \mathrm{~ms}$ (figure $3 \mathrm{~A}$ ). Although synaptic neurotransmission through the $\mathrm{GABA}_{\mathrm{A}}$ receptor mediates the second phase of SICI, ${ }^{74}{ }^{78-80}$ the precise mechanisms underlying the first phase of SICI remain uncertain. It was initially suggested that the first phase of SICI reflected local excitability properties, particularly relative refractoriness of cortical axons, with resultant resynchronisation of cortico-cortical and corticomotoneuronal volleys. ${ }^{7}{ }^{81}$ Subsequently, it has been argued that synaptic processes best explain the development of the initial phase of SICI, possibly driven by activation of cortical inhibitory circuits that were distinct to those that mediated the later SICI phase. ${ }^{767782}$

A reduction or absence of SICI, together with an increase in ICF, indicative of cortical hyperexcitability has been documented in cohorts of sporadic and familial ALS patients (figure $3 \mathrm{~A}$ ). ${ }^{30-}$

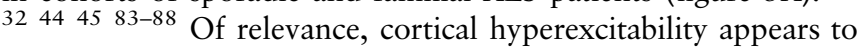
be an early feature in sporadic ALS, correlating with measures of subsequent peripheral neurodegeneration. ${ }^{30}$ In addition, cortical hyperexcitability appeared as an early feature in familial ALS due to mutations linked to the superoxide dismutase-1 (figure $3 \mathrm{~A}$ ) and fused in sarcoma (FUS) genes, ${ }^{31}$ preceding the clinical development of familial ALS (figure $3 \mathrm{~B}) .^{31}$

Neuropathological studies in ALS have identified degeneration of inhibitory cortical interneurons ${ }^{89}$ and this could account for the reduction in SICI. Separately, glutamatemediated excitotoxicity may also contribute to SICI reduction, as was suggested by partial correction of SICI abnormalities in ALS patients treated with the glutamate antagonist riluzole. ${ }^{87} \mathrm{~A}$ recent study documenting SICI reduction at low (40\% of resting MT (RMT)), medium (70\% of RMT) and high (90\% of RMT) conditioning stimulus intensities in ALS patients provided further support for the notion that abnormalities in SICI appeared to be mediated by a combination of glutamate excitotoxicity and degeneration of inhibitory cortical circuits. ${ }^{90}$ As such, preserving the integrity of intracortical inhibitory circuits, and counteracting excitatory cortical circuits, may serve as potential therapeutic options in ALS.

\section{UTILITY OF PERISTIMULUS TIME HISTOGRAMS}

A peristimulus time histogram technique can assess the function of a select subset of corticomotoneurons by recording the perturbation of voluntarily recruited motor units induced by a threshold cortical stimulation. ${ }^{53}$ In healthy controls, there is a well synchronised primary peak with a latency of approximately $20-30 \mathrm{~ms}$ recording from hand or forearm muscles. ${ }^{28} 53$ Analysis of this primary peak in disease states such as ALS provides information on corticomotoneuronal conduction time, the extent of desynchronisation of corticomotoneuronal descending volleys, the degree of corticomotoneuronal synaptic input onto the anterior horn cell and the timing of excitatory and inhibitory inputs to the motor neuron. ${ }^{33}$

In ALS, the primary peak becomes desynchronised, prolonged in duration and delayed. ${ }^{28} 9192$ In addition, the amplitude of the primary peak may be increased with additional subcomponents both suggestive of corticomotoneuronal hyperexcitability. ${ }^{53} 93$ These primary peak abnormalities appear early in ALS,
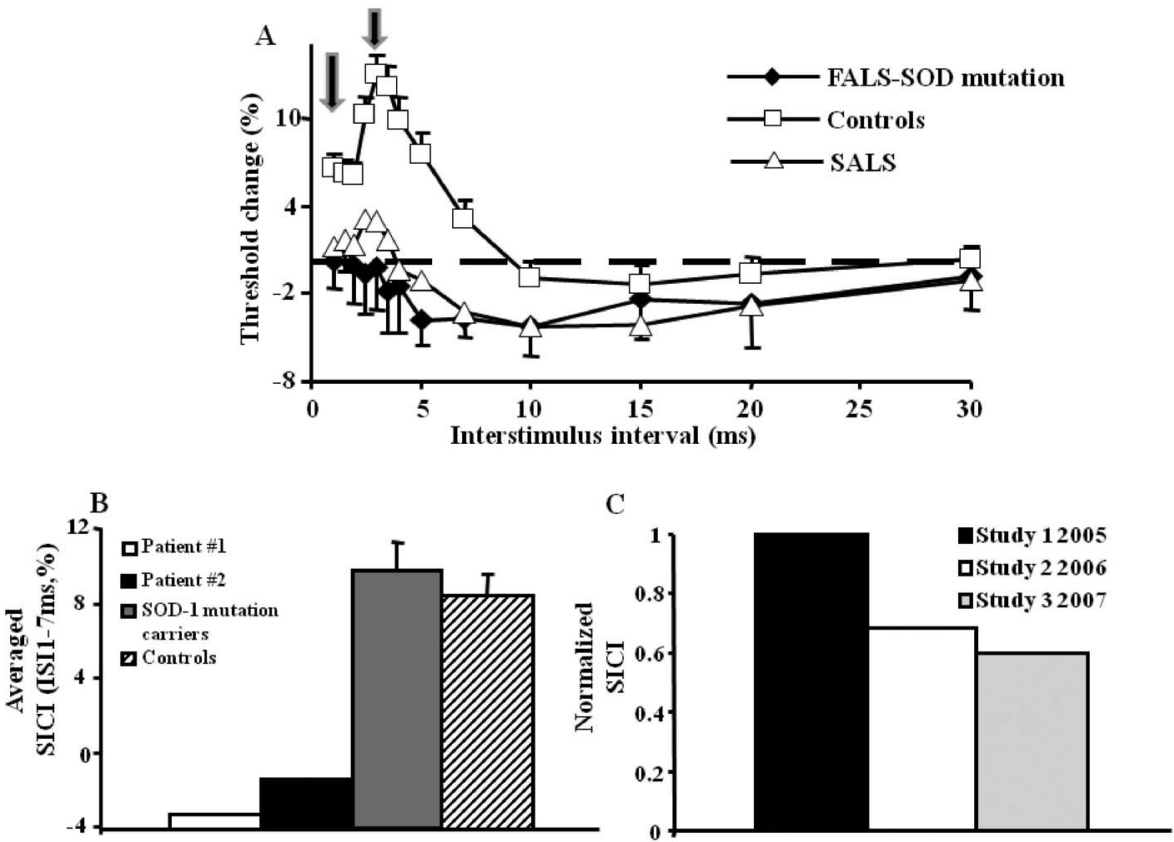

Figure 3 (A) Short interval intracortical inhibition $(\mathrm{SICl})$, defined as the stimulus intensity required to maintain a target motor evoked potential of $0.2 \mathrm{mV}$, as assessed by the threshold tracking transcranial magnetic stimulation technique. Intracortical inhibition is illustrated by an increase in the conditioned test stimulus intensity required to track the target response, while intracortical facilitation is indicated by a reduction in test stimulus intensity. In healthy controls, SICI develops between interstimulus intervals (ISI) of 1 and $7 \mathrm{~ms}$, with two peaks evident at 1 and 3 ms as indicated by the arrows. Intracortical facilitation developed between ISIs of 10 and $30 \mathrm{~ms}$. SICI is significantly reduced in both sporadic amyotrophic lateral sclerosis (SALS) and familial amyotrophic lateral sclerosis (FALS). (B) Averaged SICl, between ISI 1 and 7 ms, was reduced in two presymptomatic superoxide dismutase-1 (SOD-1) mutation carriers 6 months prior to the development of ALS. (C) Normalised SICl, expressed as a fraction of the SICI value measured at the first study, was reduced 8 months prior to development of ALS in a third presymptomatic SOD-1 mutation carrier. 
accompanied by reduced MTs. With progression of disease, there is prolongation and increased desynchronisation of the primary peak, findings possibly specific to ALS when compared with healthy controls and Kennedy's disease. ${ }^{53} 94$

\section{TRIPLE STIMULATION TECHNIQUE}

Over recent years, collision techniques such as the triple stimulation technique (TST) have been used to reduced the degree of MEP desynchronisation which normally occurs following a single cortical stimulus. ${ }^{95} 96$ This complex technique is performed by first delivering a high-intensity magnetic stimulus to motor cortex followed by supramaximal electrical stimulation of the peripheral nerve supplying the target muscle at the wrist such that the descending corticomotoneuronal volley is 'collided' out by the antidromic action potentials. Collision takes place along the proximal segment of the peripheral nerve at the upper arm. A third stimulus is subsequently delivered to Erb's point (axilla) after an appropriate delay, eliciting a highly synchronised motor response in those fibres in which the collision had occurred. The amplitude and area of this test CMAP response are compared with the response induced by the conditioned TST paradigm (Erb's point-wrist-Erb's point stimulation) yielding an amplitude ratio of $>93 \%$ and area ratio of $>92 \%$ in healthy controls. ${ }^{95} 96$

In ALS, the TST is sensitive at detecting subclinical corticomotoneuronal dysfunction. ${ }^{54} 97$ Corticomotoneuronal dysfunction was also reported in Kennedy's disease using the TST technique, ${ }^{98} 99$ potentially limiting the diagnostic utility of TST in ALS. Recently, however, a combination of TST with singleand paired-pulse TMS techniques has reaffirmed the functional integrity of corticomotoneuronal tracts in Kennedy's disease, ${ }^{100}$ and thereby the diagnostic utility of TST.

\section{DIAGNOSTIC BIOMARKER IN ALS}

Given the well documented TMS abnormalities in ALS patients, the TMS techniques may be of utility in the diagnostic process of ALS. Although UMN signs may be clinically evident in ALS, in some phenotypes such as the flail arm variant, this may not be the case, and detection of subclinical UMN dysfunction may facilitate the diagnosis. ${ }^{42}$ Abnormalities of cortical excitability, including an increase in MEP amplitude along with reduction of SICI and RMTs, have been reported in the flail-arm variant of ALS, underscoring the utility of TMS in detecting subclinical UMN dysfunction. ${ }^{42}$ Of further relevance, subclinical UMN dysfunction has been reported in progressive muscular atrophy
(PMA) ${ }^{101-103}$ suggesting that PMA may be a phenotype of ALS. While corticomotoneuronal integrity was recently reported to be intact in PMA using a $\beta$-band intermuscular coherence technique ${ }^{104}$ assessment of cortical function with TMS techniques may be of diagnostic utility, especially in light of presence of subclinical UMN pathology in PMA. ${ }^{102} 103$

Importantly, single- and paired-pulse TMS techniques reliably distinguish ALS from the mimic disorders (table 1), hastening the diagnosis of ALS by up to 8 months. ${ }^{47}$ A reduction in averaged SICI, between ISI 1 and $7 \mathrm{~ms}$, and peak SICI at ISI $3 \mathrm{~ms}$ were the most robust diagnostic TMS parameters, with the finding of absent SICI exhibiting a sensitivity of $97 \% .^{47}$ Of further relevance, TMS studies have established the presence of early and subclinical dysfunction of cortico-bulbar and cortico-respiratory tracts in ALS, ${ }^{26}{ }^{105-107}$ thereby suggesting a potential diagnostic utility of bulbar and diaphragmatic MEP recordings. In addition, combining TMS with radiological techniques, such as MR spectroscopy, may further add to the diagnostic yield especially given the sensitivity of MR spectroscopy in detecting subclinical UMN dysfunction. ${ }^{108-110}$ Consequently, combining TMS techniques, in particular the recording of SICI as well as bulbar and diaphragmatic MEPs, together with radiological techniques, such as MR spectroscopy, may enable an earlier diagnosis of ALS and thereby commencement of neuroprotective therapies and recruitment into clinical trials.

In addition to its diagnostic utility, it has been suggested that TMS may exhibit a clinical utility in assessing disease progression in ALS. ${ }^{111}$ Specifically, longitudinal TMS studies in ALS patients reported a significant reduction in MEP amplitude, MT and CMCT, and suggested that reduction in MEP amplitude may be an objective biomarker of disease progression in ALS. ${ }^{111}$ In contrast, others have failed to document any significant longitudinal changes in TMS parameters, thereby arguing against TMS utility in the monitoring of disease progression in ALS. ${ }^{52}$ Prospective longitudinal studies are indicated to further clarify the role for TMS in monitoring disease progression in ALS.

\section{CONCEPTS OF ALS PATHOPHYSIOLOGY}

In his original writings, Charcot concluded that ALS was a disorder of the brain and that the lower motor neuron component resulted from a downstream affect. Not all his contemporaries agreed and in particular Gowers was adamant that the demise of upper and lower motor neurons were independent events. In the past 2 decades the site of ALS onset has been revisited, to a large extent precipitated by the advent of TMS. Three schools

Table 1 Transcranial magnetic stimulation (TMS) techniques in amyotrophic lateral sclerosis (ALS) mimic disorders

\begin{tabular}{|c|c|c|c|c|c|c|c|}
\hline Mimic disorder & RMT & MEP amplitude & CMCT & CSP duration & SICl & ICF & TST \\
\hline Kennedy's disease & Normal & Normal & Normal & Normal & Normal & Normal & Normal and abnormal \\
\hline Acquired neuromyotonia & Normal & Normal & Normal & Normal & Normal & Normal & Not done \\
\hline DHMNP & Normal & Normal & Prolonged & Normal & Normal & Normal & Not done \\
\hline SMA & Normal & Increased & Normal & Normal & Normal & Normal & Not done \\
\hline FOSMN syndrome & Normal & Normal & Normal & Normal & Normal & Normal & Not done \\
\hline Neuromuscular disorders* & Normal & Normal & Normal & Normal & Normal & Normal & Not done \\
\hline
\end{tabular}

Single-pulse TMS studies have established a normal resting motor threshold (RMT) and cortical silent period (CSP) duration in all ALS mimic disorders. The motor evoked potential (MEP) amplitude was reported to be increased in spinal muscular atrophy (SMA), a finding attributed to greater corticomotoneuronal projections onto the surviving motor neurons. In addition, the central motor conduction time (CMCT) was reportedly prolonged in distal hereditary motor neuronopathy with pyramidal features (DHMNP). Short interval intracortical inhibition (SICI) and intracortical facilitation (ICF), assessed by the paired-pulse TMS technique, have been universally normal in ALS mimic disorders. In contrast, triple stimulation techniques

(TST) have been reportedly abnormal in Kennedy's disease, suggesting subclinical upper motor neuron dysfunction, although a recent study has reaffirmed functional integrity of corticomotoneuronal tracts in Kennedy's disease (see Utility of peristimulus time histograms section). Single- and paired-pulse techniques have also been normal in facial onset sensory motor neuronopathy (FOSMN) syndrome.

${ }^{*}$ Neuromuscular disorders include demyelinating neuropathy, myasthenia gravis, lead toxicity and Hirayama's disease. 
of thought have developed pertaining to the role of the UMN, and related pathophysiological processes in ALS: (i) 'the dying forward' hypothesis, (ii) 'the dying back' hypothesis and (iii) 'the independent degeneration' hypothesis (figure 4). While the site of disease onset in ALS remains uncertain, TMS studies have tended to favour a cortical origin, with excitotoxicity mediating motor neuron degeneration in ALS. ${ }^{5} 112$

The dying forward hypothesis proposes that ALS is primarily a disorder of the corticomotoneurons, which connect monosynaptically with anterior horn cells. ${ }^{113}$ Corticomotoneuronal hyperexcitability was postulated to induce anterior horn cell degeneration transsynaptically via an anterograde glutamatemediated excitotoxic process. ${ }^{113}$ Most TMS studies have demonstrated that cortical hyperexcitability is an early feature in sporadic and familial ALS, linked to motor neuron degeneration. $^{27} 30314365112114115$ In addition, longitudinal studies in asymptomatic SOD-1 mutation carriers revealed that cortical hyperexcitability developed prior to the clinical onset of ALS, ${ }^{31}$ also seen in the G93A SOD-1 mouse model. ${ }^{116}$ Of relevance, loss of parvalbumin-positive inhibitory interneurons in the motor cortex of ALS patients would contribute to the development of cortical hyperexcitability. ${ }^{117}$ In keeping with a cortical origin of ALS is the now accepted view that ALS and frontotemporal dementia (FTD) represent an overlapping continuum of the same disorder, ${ }^{118} 119$ an observation underscored by recent genetic findings establishing that increased hexanucleotide

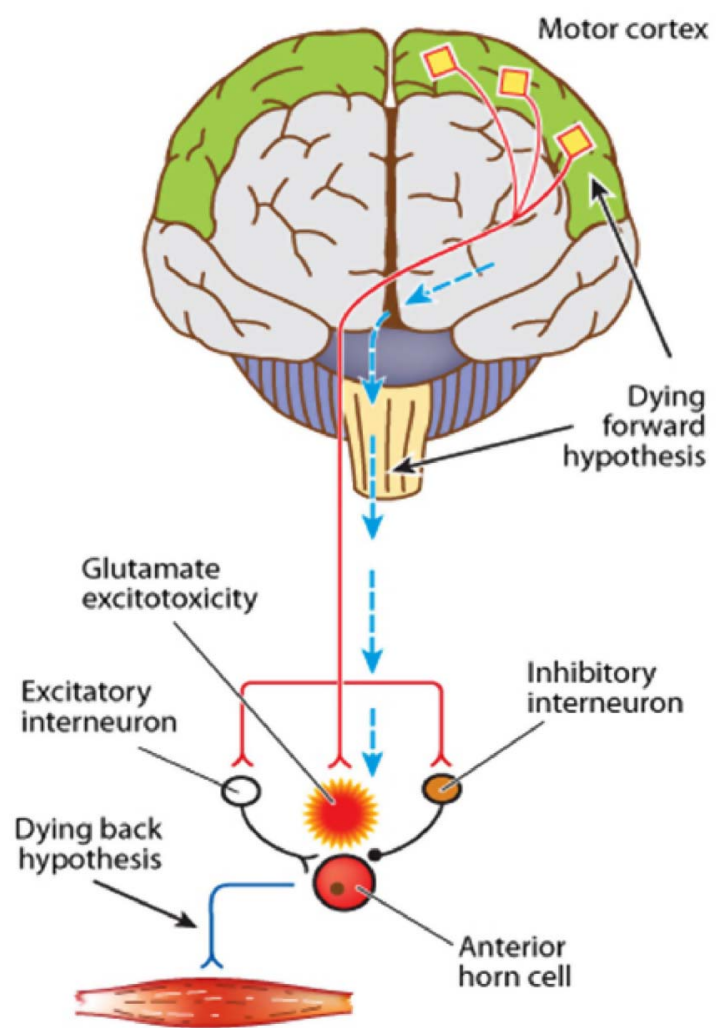

Figure 4 The dying forward and dying back hypothesis of amyotrophic lateral sclerosis (ALS). The 'dying forward' hypothesis proposed that ALS was primarily a disorder of the corticomotoneurons (highlighted in red), with anterior horn cell degeneration mediated via an anterograde glutamate-mediated excitotoxic process. In contrast, the dying back hypothesis proposes that ALS begins within the muscle or neuromuscular junction, with pathogens retrogradely transported from the neuromuscular junction to the cell body where these pathogens may exert their deleterious effects. repeat expansion in the first intron of C9ORF72 gene on chromosome 9p21 is associated with both ALS and FTD. ${ }^{120} 121$ Of further relevance, accumulation of TDP-43 ubiquitinated inclusions in anterior horn cells appears to be a pathological hallmark of ALS. ${ }^{119}{ }^{122}$ Interestingly, identical TDP-43 inclusions may also be evident in cortical neurons within the frontal (Betz cells) and temporal lobes of ALS patients, ${ }^{119} 122123$ underscoring the link between FTD and ALS, and thereby a cortical origin of ALS.

Of relevance, molecular approaches have provided further corroborating evidence for glutamate excitotoxicity in ALS. Specifically, a significant reduction in the expression and function of the astrocytic glutamate transporter, excitatory amino acid transporter 2 (EAAT2), has been reported in the SOD-1 mouse model and the motor cortex and spinal cord of ALS patients. $^{124-128}$ In addition, dysfunction of EAAT2 transporter appeared to be a preclinical feature in the SOD-1 mouse model. ${ }^{129}{ }^{130}$ Further underscoring the importance of astrocytes in ALS pathophysiology are recent stem cell studies documenting that motor neuron degeneration appears to be initiated by dysfunction of astrocytes. ${ }^{131}$

On the postsynaptic side, increased expression of glutamate receptors permeable to excessive influx of $\mathrm{Na}^{+}$and $\mathrm{Ca}^{2+}$ ions ${ }^{132}$ have been reported in ALS, ${ }^{133-137}$ potentially rendering the motor neurons more susceptible to glutamate excitotoxicity. ${ }^{138}$ Further support for a role for glutamate excitotoxicity has been indirectly provided by the clinical benefit of riluzole, a glutamate antagonist, in ALS patients. ${ }^{139-142}$

For the glutamate hypothesis to be a plausible mechanism of motor neuron degeneration, the issue of selectivity of motor neuron involvement in ALS, together with sparing of motor neurons in non-ALS conditions exhibiting cortical hyperexcitability, ${ }^{38}$ must be explained. A number of molecular features may render the motor neurons vulnerable to glutamate toxicity in ALS. First, motor neurons preferentially express glutamate receptors, such as the AMPA receptors, which are more permeable to influx of $\mathrm{Ca}^{2+}$ ions. ${ }^{133} 134136137$ In addition, motor neurons in ALS patients lack the intracellular expression of $\mathrm{Ca}^{2+}$ binding proteins parvalbumin and calbindin $\mathrm{D} 28 \mathrm{k}$, both required to buffer intracellular $\mathrm{Ca}^{2+} \cdot{ }^{143} 144$ Aberrant activity of the inositol 1,4,5-triphosphate receptor type 2 receptor has been reported in ALS, ${ }^{145} 146$ thereby resulting in higher intracellular concentrations of $\mathrm{Ca}^{2+}$ within the motor neurons. Ultimately, an influx of $\mathrm{Ca}^{2+}$ ions through the ionotropic glutamate receptors NMDA occurs in the motor neurons, ${ }^{147} 148$ resulting in increased intracellular $\mathrm{Ca}^{2+}$ concentration and activation of $\mathrm{Ca}^{2+}$-dependent enzymatic pathways that mediate neuronal death. ${ }^{149-151}$ Glutamate excitotoxicity may also result in production of free radicals that can further damage intracellular organelles and thereby cause cell death. ${ }^{152-154}$

It could be argued that the finding of widespread fasciculations in ALS, an important diagnostic criterion, ${ }^{155}$ may argue against a dying forward mechanism given that fasciculations are thought to originate from the distal motor axon, are associated with abnormalities of sodium and potassium conductance, and may precede the onset of lower motor neuron dysfunction. ${ }^{156-}$ 162 It seems unlikely that cortical hyperexcitability could lead to changes in distal axonal excitability that would result in widespread fasciculations. Importantly, a supraspinal mechanism for triggering fasciculations in ALS has been previously reported. ${ }^{34}$ In agreement with this notion are findings that fasciculations in ALS may originate at the level of the motor neuron cell body. ${ }^{157}$ As such, it could be hypothesised that hyperexcitability of descending motor pathways may contribute to generation of 
fasciculation in ALS, thereby providing additional support for a dying forward process.

In conjunction with glutamate excitotoxicity, there is compelling evidence that mitochondrial dysfunction may exert an important role in the pathophysiology of ALS. ${ }^{163-168}$ Under conditions of excessive $\mathrm{Ca}^{2+}$ load, as may be evident with glutamate excitotoxicity, ${ }^{169}$ mitochondrial production of free radicals increases resulting in injury of critical neuronal cellular proteins and DNA. Mitochondrial dysfunction may in turn enhance glutamate excitotoxicity by disrupting the normal resting membrane potential, resulting in loss of the voltagedependent $\mathrm{Mg}^{2+}$-mediated block of NMDA receptor channels. ${ }^{170}$ From a therapeutic perspective, dexpramipexole, a pharmacological agent that enhances mitochondrial function, ${ }^{171}$ was effective in slowing ALS progression in a recent phase II trial. ${ }^{172} \mathrm{~A}$ phase III, multicentre, international trial was commenced in March 2011 to determine the clinical efficacy of dexpramipexole in ALS (ClinicalTrials.gov-NCT01281189). Taken further, it is anticipated that TMS studies will be used to determine the efficacy of dexpramipexole in the modulation of cortical excitability in an attempt to provide further insight into ALS pathophysiology.

The dying back hypothesis proposes that ALS is primarily a disorder of the lower motor neurons, with pathogens retrogradely transported from the neuromuscular junction to the cell body where they exert their deleterious effects. ${ }^{173}$ Although some pathological studies have indirectly supported a dying back process, ${ }^{174-176}$ no pathogens of any type have been identified in relation to ALS. The presence of widespread dysfunction within the frontal cortex, including the primary, supplementary and prefrontal motor cortices in ALS, remains difficult to reconcile with a dying back process. ${ }^{3} 110177$ In addition, the absence of central pathology in other lower motor neuron disorders such as Kennedy's disease or poliomyelitis provides a further argument against a dying back process. ${ }^{33} 44$

The independent degeneration hypothesis suggests that the upper and lower motor neurons degenerate independently. ${ }^{178}$ Some 100 years after the original Gowers publication, neuropathological studies provided support for the independent degeneration hypothesis whereby the degeneration of upper and lower motor neurons appeared to be independent. ${ }^{179} 180$ These correlative morphological techniques, however, may be confounded by the anatomical and functional complexity of the corticomotoneuronal system. ${ }^{181}$ In particular, there remains considerable variability in the corticomotoneuronal to anterior horn cell ratio, due to synaptic changes, and as such attempts to correlate upper and lower motor neurons on autopsy studies may not be meaningful. ${ }^{33}$

In addition to the three competing theories of ALS pathogenesis, a prion-like propagation hypothesis has also been suggested. ${ }^{182}$ Specifically, the previously documented contiguous spread of ALS $^{5}{ }^{183}$ could be explained by direct neuron-to-neuron transmission of pathogenic proteins via exosomes, defined as small lipid membranous microvesicles. ${ }^{182}$ The pathogenic exosomes could spread in either a rostral direction, explaining the rostral-to-caudal spread of ALS, or in a lateral-horizontal direction accounting for the lateral-to-medial spread of disease. In addition, non-contiguous propagation of ALS could also be explained by spread of pathogenic proteins or toxic molecules through the blood or CSF via exosomes. ${ }^{182}$ Interestingly, the genes implicated in ALS pathogenesis, including TDP-43 and FUS, possess a putative prion domain. ${ }^{184}$ Although a prion-like propagation mechanism may seem an attractive explanation for the spread of ALS, at present there is no direct evidence to support such a process in ALS.
Future clinical utility of TMS

Although first described by Charcot some 150 years ago, the pathophysiological mechanisms underlying ALS, variability, rate of progression and site of disease onset remain obscure. Objective assessment of UMN function in ALS remains a difficult task in clinical neurophysiology. ${ }^{185}$ While TMS is mainly used as a clinical research tool, conducted in specialised neurophysiological laboratories, there is an urgent need to objectively assess UMN function in ALS. This has been underscored by the recent Awaji diagnostic criteria. ${ }^{155} 186$ Although needle electromyography is used by the criteria to objectively assess lower motor neuron dysfunction, the detection of UMN involvement is based solely on clinical examination. Much has recently been learnt about ALS from MRI, especially diffusion tensor MRI, functional imaging and network analysis, ${ }^{110}{ }^{187-198}$ but these tools remain prohibitively expensive, not readily available and may exhibit a modest diagnostic sensitivity. ${ }^{190}$ Commercially available TMS systems that will enable an objective assessment of UMN function could be readily developed, facilitating the diagnosis of ALS. Such TMS systems may result in the development of more functional ALS biomarkers that could be used in future drug trials for early patient recruitment and monitoring of drug efficacy.

Acknowledgements Funding support from the Motor Neuron Disease Research Institute of Australia (MNDRIA), Sylvia and Charles Viertel Charitable Foundation Clinical Investigator grant, Ramaciotti Foundation and National Health and Medical Research Council of Australia (Project grant numbers 510233 and 1024915) is gratefully acknowledged.

Contributors SV was involved in the design, research and writing of the review. UZ, $A E, M H$ and $M K$ were involved in the design, critiquing and editing of the review.

Funding Support from the Motor Neuron Disease Research Institute of Australia (MNDRIA), Sylvia and Charles Viertel Charitable Foundation Clinical Investigator grant, Ramaciotti Foundation and National Health and Medical Research Council of Australia (Project grant numbers 510233 and 1024915) is gratefully acknowledged.

\section{Competing interests None.}

Ethics approval Local ethics committee.

Provenance and peer review Commissioned; externally peer reviewed.

Open Access This is an Open Access article distributed in accordance with the Creative Commons Attribution Non Commercial (CC BY-NC 3.0) license, which permits others to distribute, remix, adapt, build upon this work non-commercially, and license their derivative works on different terms, provided the original work is properly cited and the use is non-commercial. See: http://creativecommons.org/licenses/by-nc/ $3.0 /$

\section{REFERENCES}

1 Charcot J, Joffroy A. Deux cas d'atrophie musculaire progressive avec lesion de la substance grise et des faisceaux antero-lateraux de la moelle epiniere. Arch Physiol Neurol Pathol 1869:2:744-54.

2 Kiernan MC, Vucic S, Cheah BC, et al. Amyotrophic lateral sclerosis. Lancet 2011;377:942-55.

3 Vucic S, Burke D, Kiernan MC. Diagnosis of motor neuron disease. In: Kiernan MC. ed. The motor neuron disease handbook. Sydney: Australasian Medical Publishing Company Limited, 2007:89-115.

4 Winhammar JM, Rowe DB, Henderson RD, et al. Assessment of disease progression in motor neuron disease. Lancet Neurology 2005;4:229-38.

5 Ravits J, Paul P, Jorg C. Focality of upper and lower motor neuron degeneration at the clinical onset of ALS. Neurology 2007;68:1571-5.

6 Rossini PM, Berardelli A, Deuschl G, et al. Applications of magnetic cortical stimulation. The International Federation of Clinical Neurophysiology. Electroencephalogr Clin Neurophysiol Supp/ 1999;52:171-85.

7 Fisher RJ, Nakamura Y, Bestmann S, et al. Two phases of intracortical inhibition revealed by transcranial magnetic threshold tracking. Exp Brain Res 2002;143:240-8.

8 Vucic S, Howells J, Trevillion L, et al. Assessment of cortical excitability using threshold tracking techniques. Muscle Nerve 2006;33:477-86.

9 Groppa S, Oliviero A, Eisen A, et al. A practical guide to diagnostic transcranial magnetic stimulation: report of an IFCN committee. Clin Neurophysiol 2012;123:858-82.

10 Brouwer B, Ashby P. Corticospinal projections to upper and lower limb spinal motoneurons in man. Electroencephalogr Clin Neurophysiol 1990;76:509-19. 
11 Chen R, Tam A, Butefisch C, et al. Intracortical inhibition and facilitation in different representations of the human motor cortex. J Neurophysiol 1998:80:2870-81.

12 Macdonell RA, Shapiro BE, Chiappa KH, et al. Hemispheric threshold differences for motor evoked potentials produced by magnetic coil stimulation. Neurology 1991;41:1441-4

13 Triggs WJ, Calvanio R, Levine M. Transcranial magnetic stimulation reveals a hemispheric asymmetry correlate of intermanual differences in motor performance. Neuropsychologia 1997;35:1355-63.

14 Amassian VE, Stewart M, Quirk GJ, et al. Physiological basis of motor effects of a transient stimulus to cerebral cortex. Neurosurgery 1987;20:74-93.

15 Epstein CM, Schwartzberg DG, Davey KR, et al. Localizing the site of magnetic brain stimulation in humans. Neurology 1990;40:666-70.

16 Rudiak D, Marg E. Finding the depth of magnetic brain stimulation: a re-evaluation. Electroencephalogr Clin Neurophysiol 1994;93:358-71.

17 Di Lazzaro V, Oliviero A, Profice P, et al. Ketamine increases human motor cortex excitability to transcranial magnetic stimulation. Journal of Physiology 2003;547:485-96.

18 Ziemann U. TMS and drugs. Clin Neurophysiol 2004;115:1717-29.

19 Attarian S, Azulay JP, Lardillier D, et al. Transcranial magnetic stimulation in lower motor neuron diseases. Clin Neurophysiol 2005;116:35-42.

20 Berardelli A, Inghilleri M, Cruccu G, et al. Electrical and magnetic transcranial stimulation in patients with corticospinal damage due to stroke or motor neurone disease. Electroencephalogr Clin Neurophysiol 1991;81:389-96.

21 Eisen A, Shytbel W, Murphy K, et al. Cortical magnetic stimulation in amyotrophic lateral sclerosis. Muscle Nerve 1990;13:146-51.

22 de Carvalho M, Turkman A, Swash M. Motor responses evoked by transcranial magnetic stimulation and peripheral nerve stimulation in the ulnar innervation in amyotrophic lateral sclerosis: the effect of upper and lower motor neuron lesion. J Neurol Sci 2003;210:83-90.

23 Miscio G, Pisano F, Mora G, et al. Motor neuron disease: usefulness of transcranial magnetic stimulation in improving the diagnosis. Clin Neurophysiol 1999;110:975-81.

24 Triggs WJ, Macdonell RA, Cros D, et al. Motor inhibition and excitation are independent effects of magnetic cortical stimulation. Annals of Neurol 1992:32:345-51.

25 Triggs WJ, Menkes D, Onorato J, et al. Transcranial magnetic stimulation identifies upper motor neuron involvement in motor neuron disease. Neurology 1999:53:605-11.

26 Urban P, Wicht S, Hopf H. Sensitivity of transcranial magnetic stimulation of cortico-bulbar vs. cortico-spinal tract involvement in ALS. J Neurol 2001;248:850-5

27 Caramia MD, Cicinelli P, Paradiso C, et al. 'Excitability changes of muscular responses to magnetic brain stimulation in patients with central motor disorders. Electroencephalogr Clin Neurophysiol 1991:81:243-50.

28 Kohara N, Kaji R, Kojima Y, et al. Abnormal excitability of the corticospinal pathway in patients with amyotrophic lateral sclerosis: a single motor unit study using transcranial magnetic stimulation. Electroencephalogr Clin Neurophysiol 1996;101:32-41.

29 Mills KR, Nithi KA. Corticomotor threshold is reduced in early sporadic amyotrophic lateral sclerosis. Muscle Nerve 1997;20:1137-41.

30 Vucic S, Kiernan MC. Novel threshold tracking techniques suggest that cortical hyperexcitability is an early feature of motor neuron disease. Brain 2006;129:2436-46.

31 Vucic S, Nicholson GA, Kiernan MC. Cortical hyperexcitability may precede the onset of familial amyotrophic lateral sclerosis. Brain 2008;131:1540-50.

32 Zanette $G$, Tamburin S, Manganotti $P$, et al. Different mechanisms contribute to motor cortex hyperexcitability in amyotrophic lateral sclerosis. Clin Neurophysiol 2002;113:1688-97.

33 Eisen A, Weber M. The motor cortex and amyotrophic lateral sclerosis. Muscle Nerve 2001;24:564-73.

34 Hirota N, Eisen A, Weber M. Complex fasciculations and their origin in amyotrophic lateral sclerosis and Kennedy's disease. Muscle Nerve 2000;23:1872-5.

35 Di Lazzaro V, Restuccia D, Oliviero A, et al. Magnetic transcranial stimulation at intensities below active motor threshold activates intracortical inhibitory circuits. Exp Brain Res 1998;119:265-8.

36 Devanne H, Lavoie BA, Capaday C. Input-output properties and gain changes in the human corticospinal pathway. Exp Brain Res 1997:114:329-38.

37 Ziemann U. Cortical threshold and excitability measurements. In: Eisen A. ed. Clinical neurophysiology of motor neuron diseases handbook of clinical neurophysiology. Amsterdam: Elsevier, 2004:317-35.

38 Chen $R$, Cros D, Curra A, et al. The clinical diagnostic utility of transcrania magnetic stimulation: report of an IFCN committee. Clin Neurophysiol 2008;119:504-32.

39 Hess CW, Mills KR, Murray NM, et al. Magnetic brain stimulation: central motor conduction studies in multiple sclerosis. Ann Neurol 1987;22:744-52.

40 Paulus W, Classen J, Cohen LG, et al. State of the art: pharmacologic effects on cortical excitability measures tested by transcranial magnetic stimulation. Brain Stimul 2008;1:151-63.
41 Boroojerdi B, Battaglia F, Muellbacher W, et al. Mechanisms influencing stimulus-response properties of the human corticospinal system. Clin Neurophysiol 2001;112:931-7.

42 Vucic S, Kiernan MC. Abnormalities in cortical and peripheral excitability in flail arm variant amyotrophic lateral sclerosis. J Neurol Neurosurg Psychiatry 2007;78:849-52.

43 Vucic S, Kiernan MC. Upregulation of persistent sodium conductances in familial ALS. J Neurol Neurosurg Psychiatry 2010;81:222-7.

44 Vucic S, Kiernan MC. Cortical excitability testing distinguishes Kennedy's disease from amyotrophic lateral sclerosis. Clin Neurophysiol 2008;119:1088-96.

45 Vucic S, Cheah BC, Yiannikas C, et al. Corticomotoneuronal function and hyperexcitability in acquired neuromyotonia. Brain 2010;133:2727-33.

46 Vucic S, Nicholson GA, Kiernan MC. Cortical excitability in hereditary motor neuronopathy with pyramidal signs: comparison with ALS. J Neurol Neurosurg Psychiatry 2010;81:97-100.

47 Vucic S, Cheah BC, Yiannikas C, et al. Cortical excitability distinguishes ALS from mimic disorders. Clin Neurophysiol 2011;122:1860-6.

48 Mills K. Magnetic stimulation and central conduction time. In: Eisen A. ed. Clinical neurophysiology of motor neuron diseases handbook of clinical neurophysiology. Amsterdam: Elsevier, 2004:283-93.

49 Claus D. Central motor conduction: method and normal results. Muscle Nerve 1990;13:1125-32

50 Mills KR, Murray NM. Electrical stimulation over the human vertebral column: which neural elements are excited? Electroencephalogr Clin Neurophysiol 1986:63:582-9.

51 Rossini PM, Barker AT, Berardelli A, et al. Non-invasive electrical and magnetic stimulation of the brain, spinal cord and roots: basic principles and procedures for routine clinical application. Report of an IFCN committee. Electroencephalogr Clin Neurophysiol 1994;91:79-92.

52 Mills KR. The natural history of central motor abnormalities in amyotrophic lateral sclerosis. Brain 2003;126:2558-66.

53 Eisen A, Entezari-Taher M, Stewart H. Cortical projections to spinal motoneurons: changes with aging and amyotrophic lateral sclerosis. Neurology 1996:46:1396-404.

54 Komissarow L, Rollnik JD, Bogdanova D, et al. Triple stimulation technique (TST) in amyotrophic lateral sclerosis. Clin Neurophysiol 2004;115:356-60.

55 Turner MR, Osei-Lah AD, Hammers A, et al. Abnormal cortical excitability in sporadic but not homozygous D90A SOD1 ALS. J Neurol Neurosurg Psychiatry 2005:76:1279-85.

56 Mills K. Magnetic stimulation and central conduction time. Amsterdam: Elsevier B. V., 2004.

57 Cantello R, Gianelli M, Civardi C, et al. Magnetic brain stimulation: the silent period after the motor evoked potential. Neurology 1992;42:1951-9.

58 Inghilleri M, Berardelli A, Cruccu G, et al. Silent period evoked by transcranial stimulation of the human cortex and cervicomedullary junction. J Physiol (Lond) 1993;466:521-34

59 Triggs WJ, Kiers L, Cros D, et al. Facilitation of magnetic motor evoked potentials during the cortical stimulation silent period. Neurology 1993;43:2615-20.

60 Chen R, Lozano AM, Ashby P. Mechanism of the silent period following transcranial magnetic stimulation. Evidence from epidural recordings. Exp Brain Res 1999;128:539-42.

61 Siebner HR, Dressnandt J, Auer C, et al. Continuous intrathecal baclofen infusions induced a marked increase of the transcranially evoked silent period in a patient with generalized dystonia. Muscle Nerve 1998;21:1209-12.

62 Werhahn KJ, Kunesch E, Noachtar S, et al. Differential effects on motorcortical inhibition induced by blockade of GABA uptake in humans. J Physiol (Lond) 1999:517:591-7.

63 Stetkarova I, Kofler M. Differential effects of cortical and spinal inhibitory circuits Clin Neurophysiol 2013;124:339-45.

64 Desiato MT, Caramia MD. Towards a neurophysiological marker of amyotrophic lateral sclerosis as revealed by changes in cortical excitability. Electroencephalogr Clin Neurophysiol 1997;105:1-7

65 Prout AJ, Eisen A. The cortical silent period and ALS. Muscle Nerve 1994; 17:217-23.

66 Siciliano G, Manca ML, Sagliocco L, et al. Cortical silent period in patients with amyotrophic lateral sclerosis. J Neuro/ Sci 1999;169:93-7

67 Wittstock M, Wolters A, Benecke R. Transcallosal inhibition in amyotrophic lateral sclerosis. Clin Neurophysiol 2007;118:301-7.

68 Wittstock M, Meister S, Walter U, et al. Mirror movements in amyotrophic lateral sclerosis. Amyotroph Lateral Scler 2011:12:393-7.

69 Meyer BU, Roricht S, Grafin von Einsiedel H, et al. Inhibitory and excitatory interhemispheric transfers between motor cortical areas in normal humans and patients with abnormalities of the corpus callosum. Brain 1995;118:429-40.

70 Kujirai T, Caramia MD, Rothwell JC, et al. Corticocortical inhibition in human motor cortex. J Physiol (Lond) 1993;471:501-19.

71 Hanajima R, Ugawa $Y$, Terao $Y$, et al. Paired-pulse magnetic stimulation of the human motor cortex: differences among I waves. J Physiol (Lond) 1998:509:607-18 
72 Nakamura $\mathrm{H}$, Kitagawa $\mathrm{H}$, Kawaguchi $\mathrm{Y}$, et al. Intracortical facilitation and inhibition after transcranial magnetic stimulation in conscious humans. J Physiol (Lond) 1997;498:817-23.

73 Ziemann U, Rothwell JC, Ridding MC. Interaction between intracortical inhibition and facilitation in human motor cortex. J Physiol (Lond) 1996;496:873-81.

74 Di Lazzaro V, Oliviero A, Meglio M, et al. Direct demonstration of the effect of lorazepam on the excitability of the human motor cortex. Clin Neurophysiol 2000;111:794-9.

75 Kiers L, Cros D, Chiappa KH, et al. Variability of motor potentials evoked by transcranial magnetic stimulation. Electroencephalogr Clin Neurophysiol 1993;89:415-23.

76 Vucic S, Cheah BC, Krishnan AV, et al. The effects of alterations in conditioning stimulus intensity on short interval intracortical inhibition. Brain Res 2009;1273:39-47.

77 Vucic S, Cheah BC, Kiernan MC. Dissecting the Mechanisms Underlying Short-Interval Intracortical Inhibition Using Exercise. Cereb Cortex 2011:1639-44.

78 Ziemann U, Lonnecker S, Steinhoff BJ, et al. The effect of lorazepam on the motor cortical excitability in man. Exp Brain Res 1996;109:127-35.

79 llic TV, Meintzschel F, Cleff U, et al. Short-interval paired-pulse inhibition and facilitation of human motor cortex: the dimension of stimulus intensity. J Physiol (Lond) 2002;545:153-67.

80 Di Lazzaro V, Pilato $F$, Dileone $M$, et al. GABAA receptor subtype specific enhancement of inhibition in human motor cortex. J Physiol 2006;575:721-6.

81 Hanajima R, Furubayashi T, Iwata NK, et al. Further evidence to support different mechanisms underlying intracortical inhibition of the motor cortex. Exp Brain Res 2003:151:427-34.

82 Roshan L, Paradiso GO, Chen R. Two phases of short-interval intracortical inhibition. Exp Brain Res 2003:151:330-7.

83 Hanajima R, Ugawa Y, Terao Y, et al. Ipsilateral cortico-cortical inhibition of the motor cortex in various neurological disorders. J Neurol Sci 1996;114:109-16.

84 Yokota T, Yoshino A, Inaba A, et al. Double cortical stimulation in amyotrophic lateral sclerosis. J Neurol Neurosurg Psychiatry 1996;61:596-600.

85 Ziemann U, Winter M, Reimers CD, et al. Impaired motor cortex inhibition in patients with amyotrophic lateral sclerosis. Evidence from paired transcranial magnetic stimulation. Neurology 1997:49:1292-8.

86 Sommer M, Tergau F, Wischer S, et al. Riluzole does not have an acute effect on motor thresholds and the intracortical excitability in amyotrophic lateral sclerosis. J Neurol 1999;246(Suppl 3):III22-26.

87 Stefan $\mathrm{K}$, Kunesch $\mathrm{E}$, Benecke $\mathrm{R}$, et al. Effects of riluzole on cortical excitability in patients with amyotrophic lateral sclerosis. Ann Neurol 2001;49:536-9.

88 Blair IP, Williams KL, Warraich ST, et al. FUS mutations in amyotrophic lateral sclerosis: clinical, pathological, neurophysiological and genetic analysis. J Neurol Neurosurg Psychiatry 2010;81:1286-8.

89 Nihei K, McKee AC, Kowall NW. Patterns of neuronal degeneration in the motor cortex of amyotrophic lateral sclerosis patients. Acta Neuropathologica 1993;86:55-64.

90 Vucic S, Cheah BC, Kiernan MC. Defining the mechanisms that underlie cortical hyperexcitability in amyotrophic lateral sclerosis. Exp Neurol 2009;220:177-82.

91 Eisen A, Nakajima M, Weber M. Electrophysiological studies of the corticomotoneuron in ALS. Rinsho Shinkeigaku -Clinical Neurology 1999;39:99.

92 Mills KR. Motor neuron disease. Studies of the corticospinal excitation of single motor neurons by magnetic brain stimulation. Brain 1995;118:971-82.

93 Eisen A, Nakajima M, Weber M. Corticomotorneuronal hyper-excitability in amyotrophic lateral sclerosis. J Neurol Sci 1998;160(Suppl 1):S64-68.

94 Weber M, Eisen A. Assessment of upper and lower motor neurons in Kennedy's disease: implications for corticomotoneuronal PSTH studies. Muscle Nerve 1999;22:299-306.

95 Magistris MR, Rosler KM, Truffert A, et al. A clinical study of motor evoked potentials using a triple stimulation technique. Brain 1999;122:265-79.

96 Magistris MR, Rosler KM, Truffert A, et al. Transcranial stimulation excites virtually all motor neurons supplying the target muscle. A demonstration and a method improving the study of motor evoked potentials. Brain 1998;121:437-50.

97 Kleine BU, Schelhaas HJ, van Elswijk G, et al. Prospective, blind study of the triple stimulation technique in the diagnosis of ALS. Amyotroph Lateral Scler 2010;11:67-75.

98 Attarian S, Vedel JP, Pouget J, et al. Cortical versus spinal dysfunction in amyotrophic lateral sclerosis. Muscle Nerve 2006;33:677-90.

99 Pachatz C, Terracciano C, Desiato MT, et al. Upper motor neuron involvement in X-linked recessive bulbospinal muscular atrophy. Clin Neurophysiol 2007;118:262-8.

100 Vucic S, Kiernan M. Clarifying variability of corticomotoneuronal function in Kennedy's disease. Muscle Nerve 2011;44:197-201.

101 Kim W-K, Liu X, Sandner J, et al. Study of 962 patients indicates progressive muscular atrophy is a form of ALS. Neurology 2009;73:1686-92.

102 Geser F, Stein B, Partain M, et al. Motor neuron disease clinically limited to the lower motor neuron is a diffuse TDP-43 proteinopathy. Acta Neuropathologica 2011;121:509-17

103 Ince PG, Evans J, Knopp $\mathrm{M}$, et al. Corticospinal tract degeneration in the progressive muscular atrophy variant of ALS. Neurology 2003;60:1252-8.

104 Fisher KM, Zaaimi B, Williams TL, et al. Beta-band intermuscular coherence: a novel biomarker of upper motor neuron dysfunction in motor neuron disease. Brain 2012;135:2849-64.
105 Miscio G, Gukov B, Pisano F, et al. The cortico-diaphragmatic pathway involvement in amyotrophic lateral sclerosis: neurophysiological, respiratory and clinical considerations. J Neurol Sci 2006:251:10-6.

106 Similowski T, Attali V, Bensimon G, et al. Diaphragmatic dysfunction and dyspnoea in amyotrophic lateral sclerosis. Eur Respir J 2000;15:332-7.

107 Urban PP, Vogt T, Hopf HC. Corticobulbar tract involvement in amyotrophic lateral sclerosis. A transcranial magnetic stimulation study. Brain 1998;121:1099-108.

108 Mitsumoto H, Ulug AM, Pullman SL, et al. Quantitative objective markers for upper and lower motor neuron dysfunction in ALS. Neurology 2007;68:1402-10.

109 Kaufmann P, Pullman SL, Shungu DC, et al. Objective tests for upper motor neuron involvement in amyotrophic lateral sclerosis (ALS). Neurology 2004:62:1753-7.

110 Turner MR, Kiernan MC, Leigh PN, et al. Biomarkers in amyotrophic lateral sclerosis. Lancet Neurol 2009;8:94-109.

111 Floyd AG, Yu QP, Piboolnurak P, et al. Transcranial magnetic stimulation in ALS: utility of central motor conduction tests. Neurology 2009;72:498-504.

112 Vucic S, Kiernan M. Pathophysiology of degeneration in familial amyotrophic lateral sclerosis. Curr Mol Med 2009:9:255-72.

113 Eisen A, Kim S, Pant B. Amyotrophic lateral sclerosis (ALS): a phylogenetic disease of the corticomotoneuron? Muscle Nerve 1992;15:219-24.

114 Desiato M, Bernardi G, Hagi AH, et al. Transcranial magnetic stimulation of motor pathways directed to muscles supplied by cranial nerves in ALS. Clin Neurophysiol 2002;113:132-40.

115 Eisen A, Pant B, Stewart H. Cortical excitability in amyotrophic lateral sclerosis: a clue to pathogenesis. Can J Neurol Sci 1993:20:11-6.

116 Browne SE, Yang L, DiMauro JP, et al. Bioenergetic abnormalities in discrete cerebral motor pathways presage spinal cord pathology in the G93A SOD1 mouse model of ALS. Neurobiol Dis 2006:22:599-610.

117 Nihei K, McKee AC, Kowall NW. Patterns of neuronal degeneration in the motor cortex of amyotrophic lateral sclerosis patients. Acta Neuropathologica 1993;86:55-64.

118 Lillo P, Hodges JR. Frontotemporal dementia and motor neurone disease: overlapping clinic-pathological disorders. J Clin Neurosci 2009;16:1131-5.

119 Neumann M, Sampathu DM, Kwong LK, et al. Ubiquitinated TDP-43 in Frontotemporal Lobar Degeneration and Amyotrophic Lateral Sclerosis. Science 2006:314:130-3.

120 Renton Alan E, Majounie E, Waite A, et al. A Hexanucleotide Repeat Expansion in C9ORF72 Is the Cause of Chromosome 9p21-Linked ALS-FTD. Neuron 2011;72:257-68.

121 DeJesus-Hernandez M, Mackenzie lan R, Boeve Bradley F, et al. Expanded GGGGCC Hexanucleotide Repeat in Noncoding Region of C90RF72 Causes Chromosome 9p-Linked FTD and ALS. Neuron 2011;72:245-56.

122 Arai T, Hasegawa M, Akiyama $\mathrm{H}$, et al. TDP-43 is a component of ubiquitin-positive tau-negative inclusions in frontotemporal lobar degeneration and amyotrophic lateral sclerosis. Biochem and Biophy Res Commun 2006:351:602-11.

123 Tsuji H, Arai T, Kametani F, et al. Molecular analysis and biochemical classification of TDP-43 proteinopathy. Brain 2012;135:3380-91.

124 Boillee S, Vande Velde C, Cleveland DW. ALS: a disease of motor neurons and their nonneuronal neighbors. Neuron 2006;52:39-59.

125 Ionov ID. Survey of ALS-associated factors potentially promoting $\mathrm{Ca}(2+)$ overload of motor neurons. Amyotroph Lateral Scler 2007;8:260-5.

126 Rothstein JD, Jin L, Dykes-Hoberg M, et al. Chronic inhibition of glutamate uptake produces a model of slow neurotoxicity. Proc Natl Acad Sci U S A 1993:90:6591-5.

127 Rothstein JD, Van Kammen M, Levey Al, et al. Selective loss of glial glutamate transporter GLT-1 in amyotrophic lateral sclerosis. Ann Neurol 1995:38:73-84.

128 Trotti D, Rolfs A, Danbolt NC, et al. SOD1 mutants linked to amyotrophic lateral sclerosis selectively inactivate a glial glutamate transporter. Nat Neurosci 1999;2:848.

129 Boston-Howes W, Gibb SL, Williams EO, et al. Caspase-3 cleaves and inactivates the glutamate transporter EAAT2. J Biol Chem 2006;281:14076-84.

130 Gibb SL, Boston-Howes W, Lavina ZS, et al. A Caspase-3-cleaved Fragment of the Glial Glutamate Transporter EAAT2 Is Sumoylated and Targeted to Promyelocytic Leukemia Nuclear Bodies in Mutant SOD1-linked Amyotrophic Lateral Sclerosis. J Biol Chem 2007:282:32480-90.

131 Haidet-Phillips AM, Hester ME, Miranda CJ, et al. Astrocytes from familial and sporadic ALS patients are toxic to motor neurons. Nat Biotech 2011;29:824-8.

132 Simeone TA, Sanchez RM, Rho JM. Molecular biology and ontogeny of glutamate receptors in the mammalian central nervous system. J Child Neurol 2004;19:343-60.

133 Kawahara Y, Ito K, Sun $\mathrm{H}$, et al. Glutamate receptors: RNA editing and death of motor neurons. Nature 2004:427:801.

134 Kwak S, Kawahara Y. Deficient RNA editing of GluR2 and neuronal death in amyotropic lateral sclerosis. J Mol Med 2005;83:110-20.

135 Takuma H, Kwak S, Yoshizawa T, et al. Reduction of GluR2 RNA editing, a molecular change that increases calcium influx through AMPA receptors, selective in the spinal ventral gray of patients with amyotrophic lateral sclerosis. Ann Neurol 1999:46:806-15. 
136 Van Damme P, Braeken D, Callewaert G, et al. GluR2 deficiency accelerates motor neuron degeneration in a mouse model of amyotrophic lateral sclerosis. J Neuropathol Exp Neurol 2005:64:605-12.

137 Van Damme P, Van Den Bosch L, Van Houtte E, et al. GluR2-dependent properties of AMPA receptors determine the selective vulnerability of motor neurons to excitotoxicity. J Neurophysiol 2002;88:1279-87.

138 Williams TL, Day NC, Ince PG, et al. Calcium-permeable alpha-amino-3-hydroxy-5-methyl-4-isoxazole propionic acid receptors: a molecular determinant of selective vulnerability in amyotrophic lateral sclerosis. Ann Neurol 1997:42:200-7.

139 Bensimon G, Lacomblez L, Meininger V, ALS/Riluzole Study Group. A controlled trial of riluzole in amyotrophic lateral sclerosis. N Engl J Med 1994;330:585-91.

140 Gurney ME, Cutting FB, Zhai $\mathrm{P}$, et al. Benefit of vitamin E, riluzole, and gabapentin in a transgenic model of familial amyotrophic lateral sclerosis. Ann Neurol 1996;39:147-57.

141 Gurney ME, Fleck TJ, Himes CS, et al. Riluzole preserves motor function in a transgenic model of familial amyotrophic lateral sclerosis. Neurology 1998;50:62-6.

142 Lacomblez L, Bensimon G, Leigh PN, et al. Amyotrophic Lateral Sclerosis/Riluzole Study Group II. Dose-ranging study of riluzole in amyotrophic lateral sclerosis. Lancet 1996;347:1425-31.

143 Alexianu ME, Ho BK, Mohamed AH, et al. The role of calcium-binding proteins in selective motoneuron vulnerability in amyotrophic lateral sclerosis. Ann Neurol 1994;36:846-58

144 Ince $\mathrm{P}$, Stout N, Shaw $\mathrm{P}$, et al. Parvalbumin and calbindin D-28k in the human motor system and in motor neuron disease. Neuropathol Appl Neurobiol 1993;19:291-9.

145 Choe CU, Ehrlich BE. The inositol 1,4,5-trisphosphate receptor (IP3R) and its regulators: sometimes good and sometimes bad teamwork. SCi STKE 2006;2006:re15.

146 van Es MA, Van Vught PW, Blauw HM, et al. ITPR2 as a susceptibility gene in sporadic amyotrophic lateral sclerosis: a genome-wide association study. Lancet Neurol 2007;6:869-77.

147 Choi DW. Ionic dependence of glutamate neurotoxicity. J Neurosci 1987;7:369-79.

148 Miller RJ, Murphy SN, Glaum SR. Neuronal Ca2+ channels and their regulation by excitatory amino acids. Ann N Y Acad Sci 1989;568:149-58.

149 Meldrum B, Garthwaite J. Excitatory amino acid neurotoxicity and neurodegenerative disease. Trends Pharmacol Sci 1990;11:379-87.

150 Regan RF, Panter SS, Witz A, et al. Ultrastructure of excitotoxic neuronal death in murine cortical culture. Brain Res 1995;705:188-98.

151 Shaw P, Kuncl WR. Current concepts in the pathogenesis of ALS. In: WR K. ed. Motor neuron disease. Lodon: WB Saunders, 2002:37-73.

152 Bondy SC, Lee DK. Oxidative stress induced by glutamate receptor agonists. Brain Res 1993;610:229-33.

153 Lees GJ. Contributory mechanisms in the causation of neurodegenerative disorders. Neuroscience 1993;54:287-322.

154 Maher $\mathrm{P}$, Davis JB. The role of monoamine metabolism in oxidative glutamate toxicity. J Neurosci 1996;16:6394-401.

155 de Carvalho M, Dengler R, Eisen A, et al. Electrodiagnostic criteria for diagnosis of ALS. Clin Neurophysiol 2008;119:497-503.

156 de Carvalho M, Naka D, Mills KR, et al. Pathophysiological significance of fasciculations in the early diagnosis of ALS. Amyotroph Lateral Scler Other Motor Neuron Disord 2000;1(Suppl 1):S43-6.

157 Kleine BU, Stegeman DF, Schelhaas HJ, et al. Firing pattern of fasciculations in ALS: evidence for axonal and neuronal origin. Neurology 2008;70:353-9.

158 Mills KR. Characteristics of fasciculations in amyotrophic lateral sclerosis and the benign fasciculation syndrome. Brain 2010;133:3458-69.

159 Bostock H, Sharief MK, Reid G, et al. Axonal ion channel dysfunction in amyotrophic lateral sclerosis. Brain 1995;118:217-25.

160 Kanai K, Kuwabara S, Misawa S, et al. Altered axonal excitability properties in amyotrophic lateral sclerosis: impaired potassium channel function related to disease stage. Brain 2006;129:953-62.

161 Kanai K, Shibuya K, Sato Y, et al. Motor axonal excitability properties are strong predictors for survival in amyotrophic lateral sclerosis. I Neurol Neurosurg Psychiatry 2012;83:734-8.

162 Vucic S, Kiernan MC. Axonal excitability properties in amyotrophic lateral sclerosis. Clin Neurophysiol 2006;117:1458-66.

163 Boillee S, Vande Velde C, Cleveland DW. ALS: a disease of motor neurons and their nonneuronal neighbors. Neuron 2006:52:39-59.

164 Chung MJ, Suh YL. Ultrastructural changes of mitochondria in the skeletal muscle of patients with amyotrophic lateral sclerosis. Ultrastruct Pathol 2002;26:3-7.

165 Higgins CM, Jung C, Xu Z. ALS-associated mutant SOD1G93A causes mitochondrial vacuolation by expansion of the intermembrane space and by involvement of SOD1 aggregation and peroxisomes. BMC Neurosci 2003;4:16.

166 Kirkinezos IG, Bacman SR, Hernandez D, et al. Cytochrome $\mathrm{c}$ association with the inner mitochondrial membrane is impaired in the CNS of G93A-SOD1 mice. J Neurosci 2005;25:164-72.

167 Lederer CW, Torrisi A, Pantelidou M, et al. Pathways and genes differentially expressed in the motor cortex of patients with sporadic amyotrophic lateral sclerosis. BMC Genomics 2007;8:26
168 Xu Z, Jung C, Higgins C, et al. Mitochondrial degeneration in amyotrophic lateral sclerosis. J Bioenerg Biomembr 2004;36:395-9.

169 Dugan LL, Choi DW. Excitotoxicity, free radicals, and cell membrane changes. Ann Neurol 1994;35:S17-21.

170 Heath PR, Tomkins J, Ince PG, et al. Quantitative assessment of AMPA receptor mRNA in human spinal motor neurons isolated by laser capture microdissection. Neuroreport 2002:13:1753-7.

171 Cheah BC, Kiernan MC. Dexpramipexole, the $R(+)$ enantiomer of pramipexole, for the potential treatment of amyotrophic lateral sclerosis. IDrugs 2010;13:911-20.

172 Cudkowicz M, Bozik ME, Ingersoll EW, et al. The effects of dexpramipexole (KNS-760704) in individuals with amyotrophic lateral sclerosis. Nat Med 2011;17:1652-6.

173 Chou SM, Norris FH. Amyotrophic lateral sclerosis: lower motor neuron disease spreading to upper motor neurons. Muscle Nerve 1993;16:864-9.

174 Gould TW, Buss RR, Vinsant S, et al. Complete dissociation of motor neuron death from motor dysfunction by Bax deletion in a mouse model of ALS. J Neurosci 2006;26:8774-86

175 Pagani MR, Reisin RC, Uchitel OD. Calcium signaling pathways mediating synaptic potentiation triggered by amyotrophic lateral sclerosis IgG in motor nerve terminals. J Neurosci 2006;26:2661-72.

176 Pun S, Santos AF, Saxena S, et al. Selective vulnerability and pruning of phasic motoneuron axons in motoneuron disease alleviated by CNTF. Nat Neurosci 2006;9:408-19.

177 Miller RG, Jackson CE, Kasarskis EJ, et al. Practice parameter update: the care of the patient with amyotrophic lateral sclerosis: multidisciplinary care, symptom management, and cognitive/behavioral impairment (an evidence-based review): report of the Quality Standards Subcommittee of the American Academy of Neurology. Neurology 2009;73:1227-33.

178 Gowers WR. A Manual of Diseases of the Nervous System: spinal cord and nerves. In. London: Churchill, 1888:356-381.

179 Kiernan J, Hudson A. Changes in sizes of cortical and lower motor neurons in amyotrophic lateral sclerosis. Brain 1991:843-53.

180 Pamphlett R, Kril J, Hng T. Motor neuron disease: a primary disorder of corticomotoneurons? Muscle Nerve 1995:314-18.

181 Flament D, Goldsmith P, Buckley CJ, et al. Task dependence of responses in first dorsal interosseous muscle to magnetic brain stimulation in man. J Physiol 1993:464:361-78.

182 Kanouchi T, Ohkubo T, Yokota T. Can regional spreading of amyotrophic lateral sclerosis motor symptoms be explained by prion-like propagation? I Neurol Neurosurg Psychiatry 2012;83:739-45.

183 Fujimura-Kiyono C, Kimura F, Ishida S, et al. Onset and spreading patterns of lower motor neuron involvements predict survival in sporadic amyotrophic lateral sclerosis. J Neurol Neurosurg Psychiatry 2011;82:1244-9.

184 King OD, Gitler AD, Shorter J. The tip of the iceberg: RNA-binding proteins with prion-like domains in neurodegenerative disease. Brain Res 2012:1462:61-80.

185 de Carvalho M. Testing upper motor neuron function in amyotrophic lateral sclerosis: the most difficult task of neurophysiology. Brain 2012;135:2581-2.

186 Costa J, Swash M, de Carvalho M. Awaji criteria for the diagnosis of amyotrophic lateral sclerosis: a systematic review. Arch Neurol 2012:1-7.

187 Udaka F, Sawada H, Seriu N, et al. MRI and SPECT findings in amyotrophic lateral sclerosis. Demonstration of upper motor neurone involvement by clinical neuroimaging. Neuroradiology 1992;34:389-93.

188 Ellis CM, Simmonds A, Jones D, et al. Diffusion tensor MRI assesses corticospinal tract damage in ALS. Neurology 1999;53:1051-8.

189 Ellis CM, Simmons A, Andrews C, et al. A proton magnetic resonance spectroscopic study in ALS: correlation with clinical findings. Neurology 1998:51:1104-9.

190 Foerster BR, Dwamena BA, Petrou M, et al. Diagnostic accuracy using diffusion tensor imaging in the diagnosis of ALS: a meta-analysis. Acad Radiol 2012;19:1075-86

191 Verstraete E, Veldink JH, Hendrikse J, et al. Structural MRI reveals cortical thinning in amyotrophic lateral sclerosis. J Neurol Neurosurg Psychiatry 2012;83:383-8.

192 Cosottini M, Pesaresi I, Piazza S, et al. Structural and functional evaluation of cortical motor areas in Amyotrophic Lateral Sclerosis. Exp Neurol 2012;234:169-80.

193 Rose S, Pannek K, Bell C, et al. Direct evidence of intra- and interhemispheric corticomotor network degeneration in amyotrophic lateral sclerosis: an automated MRI structural connectivity study. Neurolmage 2012;59:2661-9.

194 Turner MR, Hammers A, Al-Chalabi A, et al. Distinct cerebral lesions in sporadic and 'D90A' SOD1 ALS: studies with [11C]flumazenil PET. Brain 2005;128:1323-9.

195 Turner MR, Rabiner EA, Hammers A, et al. [11C]-WAY100635 PET demonstrates marked 5-HT1A receptor changes in sporadic ALS. Brain 2005;128:896-905.

196 Tsujimoto M, Senda J, Ishihara T, et al. Behavioral changes in early ALS correlate with voxel-based morphometry and diffusion tensor imaging. J Neurol Sci 2011:307:34-40.

197 Turner MR, Grosskreutz J, Kassubek J, et al. Towards a neuroimaging biomarker for amyotrophic lateral sclerosis. Lancet Neurol 2011;10:400-3.

198 Turner MR, Modo M. Advances in the application of MRI to amyotrophic lateral sclerosis. Expert Opin Med Diagn 2010;4:483-96. 